\title{
Beyond the Mantra of Empowerment: Time to Return to Poverty, Violence and Struggle
}

\author{
Uma Chakravarti
}

\begin{abstract}
1 Introduction
Since the middle of the 1970s, dual processes have raised, with renewed vigour, the question of women's development - or the lack thereof - in the public domain in India: the movement for women's autonomy and rights, and policies of the state specifically targeting women. Both processes were given a fillip with the publication in 1975 of the Status of Women Report, which drew attention to the abysmal indices of women's development: declining sex ratio and declining work participation in particular. But the reaction of the women's movement, which was already under way when the report was published, was very different from that of the state. The movement confronted the structures of patriarchy and class, which were understood to be directly responsible for the grim conditions under which women existed, while the state, with its characteristic paternalism, sought to bring women into the development process, while castigating them for remaining outside the process through their own inertia and backwardness.
\end{abstract}

This article will explore the conflicted relationship between the women's movement - with a specific location in feminism - and other people's movements on the one hand, and the changing policies of the state on the other, through an indepth analysis of three programmes - the Women's Development Programme (WDP) in Rajasthan, the Total Literacy Campaign (TLC) in Andhra Pradesh, and the focus on self-help groups (SHG) in Gujarat and Andhra Pradesh. The three programmes also represent three moments in the recent history of 'women's' development in India.
2 The Women's Development Programme (WDP)

The critical question for the women's movement in the late 1970s and early 1980s was the mode of development adopted by the post-colonial nationstate in India and the focus of all democratic movements was to highlight the categories of people who were excluded from the 'gains' of development. $A$ number of issues were thrown up: was growth happening, was the trickle-down theory working, was inequality diminishing or growing, and what was happening to the weakest segments of society within the process of development - dalits, adivasis/'tribals', the poor and women?

At the same time, the women's movement in particular was raising and confronting the issue of violence in the everyday lives of women. This violence against women was understood to be located at many sites - the family, the community and the state, and was perceived to be a major obstruction in 'development' as a process.

For all of these reasons, when the opportunity arose in the mid-1980s to collaborate with the state in an innovative women's development programme in Rajasthan - the WDP - a section of the women's movement was drawn into it. The autonomous women's movement conceptualised violence against women as a critical element in the working of patriarchy and had contributed to the reactivation and energising of the older women's groups affiliated to left political parties. It functioned in a sense as the 'think tank' of the broad range of women's groups constituting what may be termed the left-democratic women's movement. Activists saw the Rajasthan programme as a means of 
reaching out to a large number of women, especially in the rural areas, who were not easily accessible to the largely urban centred, middle-class base of the autonomous women's movement.

As the WDP unfolded in Rajasthan it came to be popularly called the 'Sathin' programme as it was the sathins who came to be the lifeblood of the programme. I have written about this programme elsewhere in some detail (Chakravarti 2005), so I will restrict myself to the issues raised by the functioning and later the collapse of the programme.

Begun with great creative energy, the WDP tried to bring the state, women's groups, and research agencies together to reach out to the grassroots. It would identify women from the poorest and lowest segments of rural society - as they were the worst affected by the violence of both patriarchy and 'claste' (caste and class) as a young friend from Bihar terms it - as the 'agents' of change. They were to be called the sathins, meaning compatriot or friend.

The sathin was first to undergo a rigorous and intensive person-centred training to 'become' the agent of change. Empowerment was not yet the buzzword (it emerged in the 1990s in UNDP circles), so the thrust of the training was a process of change whereby women would take control over their own lives giving them a measure of autonomy and agency in transforming the lives of other women like them. Sathins later recalled the heady days of these training sessions when women like Aruna Roy and Kavita Srivastava (who have been active in the right to information campaign and the civil liberties movement apart from their engagement with the women's movement) lived and participated with them in a workshop as resource persons/trainers, both challenging them and building confidence and understanding which they have put to great creative use for over two decades.

The WDP linked three levels of the administration: the village, the block, and the district. This meant that while there was only one sathin in a village, she drew upon the strength and resources of other sathins from villages from her own neighbourhood, and located across the state, as well as block and district level women in the WDP and most importantly, the official governmental administrators. This had great effect - the energy came from the women in the WDP and the legitimacy and clout with the police and other agencies came from the administration. In the early stages of the programme, this resulted in a successful chain of linkages which was further enhanced by a newspaper brought out by the sathins that built awareness among women through its circulation in those districts that had introduced the WDP. In addition, every village with a sathin held a village level meeting of all the women to identify issues that needed to be taken up. The sathin of the village was to pursue these and take them up to the collective of sathins at the district level.

According to the narratives of the sathins, the WDP recognised the centrality of violence in the lives of women and hence occupied a major chunk of their activities. There were cases of extreme violence rapes, 'domestic' violence, incest, forced incarceration - apart from the denial of rights to food, resources and healthcare. Innovative strategies were used to reach women who were secluded under cultural taboos but often also incarcerated under the diktats of family patriarchs.

For example, on one occasion a street play was performed at the doorstep of a house where a daughter had been 'imprisoned', depicting the same situation as that of the daughter. Tension filled the air and there was danger of violence against the sathins. Finally, the mother of the girl was moved to join the women at the doorway. That broke the fear and tipped the balance with the audience as a number of other villagers came out to join the protesters/rescuers. Another woman had been locked into a crude improvised undergarment so that the husband secured her chastity during his absence from the village and was rescued by sathins. The rape of a woman was sought to be 'settled' through a decision on the matter by the patriarchs of the village: the sathins refused to accept this and a criminal case against the accused was filed - and there were countless stories of this kind that sathins and block level activists of the WDP recounted to me as they described the early workings of the WDP in the years 1986-9.

Soon, however, contradictions surfaced: during the early discussions in the workshops with the sathins in the WDP, two issues emerged as critical in the lives of poor women: land - or the need for productive resources; and health. 
The denial of land and the demand for it was regarded by district level officials of the government and the district level non-governmental organisation (NGO) as too sensitive and so was quickly dropped. It was decided that the issue of health could be taken up as it was 'less political'.

But, as it turned out, everything that is an area of critical concern to women's autonomy is bound to be regarded as political. Trouble began when the sathins' understanding of bodily autonomy conflicted with that of district officials and those higher up in the government administration. During a severe drought, the administration linked participation in the food-for-work programme of the state to accepting sterilisation in order to further family planning targets. The sathins protested about this and were severely reprimanded. The sathins discovered that not only did the family and community 'own' women's bodies, so did the state. At the same time, the sathins raised economic and political demands such as minimum wages for all, including themselves, secure tenure like other government functionaries, and the right to form an organised collective.

The power hierarchy that the sathins brought under their scrutiny, the issue of minimum wages, and the resistance to the linking of food to compulsory sterilisation, pitted the sathins against the state and its limited notion of development. The WDP collapsed; government officials decided that the 'heady process of discovering themselves' had led to the 'loss of the maturity required to play a low key role' among the sathins in development - which is perhaps all that the state had intended all along.

Over the 1990s, the programme was, in the words of the sathins, 'slow poisoned', and remains a shell of its former self. New programmes have replaced the sathin as the agent of change with groups of women (drawn notionally from all castes but in practice eliding the lowest castes), which are increasingly turned into selfhelp groups, an issue I will deal with in the last section of this article. The problem of violence against women has simply dropped off the radar screen; while the sathins have faced severely restrictive and even punitive measures from the state they were celebrated as the model of successful empowerment in Beijing by the very same government in order to claim kudos for itself! Back home in Rajasthan, the government continues to deny minimum wages and a stable tenure to the sathins on the ground that they are illiterate.
From being active agents in the struggle against patriarchy, caste and class inequalities, the sathins have been reduced to becoming extension workers who are chased by every line department to execute every government programme - from enrolling girls in school, to backing the pulse polio campaigns, and fulfilling government targets for whatever programme is currently being implemented, whether it has anything to do with women's development or not.

The sathins and activists of the women's movement have also learnt a harsh truth: the state has the power to initiate a development programme and to bury it when it chooses. Women are either recipients of development, or instruments, never agents of development as they understand and conceptualise it.

\section{The Total Literacy Campaign (TLC)}

The 'fact' of the illiteracy of the sathins, which was used against them to deny them rights, forms a useful linking point to move on to another important campaign intervening in the arena of development: the literacy campaigns of the late 1980s and early 1990s. The Total Literacy Campaign was a government campaign, but its emphasis on the mobilisation of the masses gave it many elements of a new radical measure. The campaign was inspired by the success of post-revolutionary literacy campaigns in Cuba, Guinea Bissau and Nicaragua, and Paolo Frere's 'conscientisation' was for a while the buzzword in government circles.

The TLC also coincided with the beginning of the era of liberalisation and other major structural changes in the Indian economy. Nevertheless, for middle-class activists the campaign appeared to be, for various reasons, a space to work with government. The 'space' theory created a new kind of optimism among intellectuals and women's groups who were critical of the 'cynics' for what they called their 'endless suspicion' about the role of the state (Saxena 2002: 74).

But, as was soon to become apparent, working with the government had its contradictions. Even in its ideological rhetoric, now centred on 'empowerment' rather than on redistribution of resources, the latter was at best Janus-faced. Not surprisingly, the campaign reinforced official stereotypes about the underprivileged, holding them responsible for their own condition through rampant and irresponsible 
reproduction, as well as suggesting that literacy would end exploitation and poverty. Advertisements in the media played upon this theme endlessly - a woman domestic servant being liberated by learning how to sign her name and open a bank account, to live happily ever after through the paternalistic efforts of her mistress; or a little street urchin learning how to read the alphabet and running away onto the road to freedom. The emphasis on the functional skills of literacy and numeracy thus masked and trivialised the complex social reality in which the poor and the excluded were placed and the structural conditions that placed them there. By focusing on individual selfimprovement it reinforced a specifically neoliberal notion of empowerment

And yet there appeared to be great possibilities in the TLC. The content of the syllabus for adult learners is necessarily different from that of conventional school syllabi and since the TLC included a component of building self-reliance through 'awareness-building', such that the neoliterates would become aware of the causes of their deprivation, and move towards amelioration through organisation and participation in the process of development, it drew large numbers of young volunteers to join the campaign - much like the Nicaraguan brigadistas.

Unfortunately however, the model as it unfolded in India relied heavily on district level bureaucracy. Furthermore, the handbook on the development of curriculum materials stated that there would be two types of materials - core content and locally relevant content. The core content had to conform to certain non-negotiables: national integration, women's equality and population education, i.e. the imbibing of the small family norm. Predictably, therefore, a number of primers emphasised a 'linear causal relationship, linking all problems from gender discrimination, poverty, unemployment, underdevelopment and environmental degradation to overpopulation' (Saxena 2007: 420). A truckload of primers building a doomsday scenario where the poor were dragging humanity down through their illiteracy and the consequent growth of population was dumped in field offices in one centre. It is no surprise then that young dalit girls in a literacy class held themselves responsible for their poverty and low status (Saxena 2007: 427-8).

The locally relevant content however had possibilities contingent on local level conjunctures: this was the context for the eruption of the famous anti-arrack (alcohol) women's agitation in Nellore, clearly an incidental rather than planned fallout of the TLC, which merits some attention from the point of view of the issues raised in this article.

The anti-arrack agitation was a local women's response to the education programme initiated for them by the state. The political economy of arrack in the state of Andhra Pradesh has been marvellously and insightfully documented by a number of writers and is an important element in understanding the relationship between the literacy classes and the eruption of the anti-arrack agitation. The story of its beginnings is now part of folklore, widely reported in the newspapers and other media, and tells how some drunken men tried to disrupt a women's literacy meeting in the village of Dubbagunta. One story, which is part of the locally relevant content of the primers used in the literacy class, recounts how a villager called Seethamma was unable to reform her drunken husband and committed suicide - this is not a true story but one specially created for the primer by the women's group, Andhra Mahila Sabha. Such suicides were a social reality. This story deeply affected the women of Dubbagunta who got together and started an organised struggle against arrack in the village. $A$ leading part was played by Rosamma, who was in the women's literacy group, but whose husband had died due to cirrhosis of the liver.

The spontaneous struggle quickly spread throughout the district and ultimately the state, using the infrastructure of the literacy programme. TLC volunteers and state government functionaries were in a sense forced to take up the agitation as women who had gathered for the literacy classes in numerous villages demanded support from them in the anti-liquor campaign. The state government was the primary target of the movement for its policies of promoting liquor sales for the revenues it brought in. The Dubbagunta story itself became the basis of another lesson in a post-literacy primer entitled 'When Women Unite'. During the highest phase of the movement, the auction for the arrack contract could not be conducted in many areas; in one district, the auction was postponed 32 times. Finally, the district collector there was transferred and it was widely believed that this was done at the behest of the liquor contractors. 
As the anti-liquor campaign spread and the issue hit the public domain - it even became an election issue - the state government, which was the target of the women's ire, came down heavily on the Nellore TLC. The primer containing the Dubbagunta story was withdrawn, and the collector - the administrative head of the district unit of the government - sent out an order stating that the anti-arrack agitation was an anti-government activity which the literacy staff were not to participate in. The agitation itself faced strong repression especially where women were succeeding in stalling the auctioning of contracts. Finally, more underhand methods were used to break the morale of the women. A rumour was floated that the government's subsidised rice for the poor would be stopped in those villages where women were preventing the entry of liquor; a collusion between the liquor barons and state officials threatened to pit food for survival against the free sale of liquor to break the resistance of the women. Nevertheless, for a while the anti-arrack campaign of women did succeed, as the government was forced to ban the production and sale of arrack in Andhra Pradesh.

The ban was partially lifted in 1996 and at the same time under a new initiative entitled 'taking the government to the people', women's credit and thrift societies - the famous self-help groups (SHGs) were started at the village level. At this time, in India microcredit and SHGs were seen as the sole means of empowerment for women, the magic wand by which poor women could be delivered from their economic distress - and they would ask no questions of the state. Adult women's education, which was the focus of the TLC, is a vanishing agenda; funding has shifted to the adolescent girl who is regarded as a better target for fertility awareness. This has led to anger and a sense of betrayal among some adult women who are quickly lapsing into non-literate status, as they have no continuing reading practice (Sharma et al. 2007: 9).

\section{Self-help groups (SHGs)}

According to an evaluation of the SHG schemes by Nirantar, a feminist educational organisation (Sharma et al. 2007), the SHG model of microcredit represents a heady mix of possibilities: empowerment of women, space for social and political participation, immediate and tangible increase in credit for the poor (avoiding the humiliations of going to the moneylender who was until recently the only means of accessing credit for the poor), and the inclusion of the poor in selfinitiated and productive economic activity.

But precisely since hopes are high, it is necessary that the SHG phenomenon is understood and analysed: what is actually happening as a consequence of the formation and proliferation of SHGs? It is particularly necessary to ask this question, since 90 per cent of the SHGs are comprised solely of women, and the claim is that SHGs have the potential to fundamentally transform women's lives. The Nirantar report, based on a study of two states, Andhra Pradesh and Gujarat, and with close interaction of a number of NGOs working in the field, argues that while access to equitable credit is a person's right, and delivering it to those who need it is a desirable achievement, it cannot be the only criteria by which to measure the impact of SHGs on women's lives. The Nirantar report interestingly uses the lens of education - defined broadly as the 'learning processes including literacy, access to information, processes of critical reflection that enable the learners to make linkages between women's lived realities and the larger structures and ideologies that they are located in' (Sharma et al. 2007: 5). Using this lens, and placing women at the centre, the Nirantar study evaluates the claims and espoused goals of the SHGs: empowerment and poverty alleviation.

Further, the Nirantar study examines the consequent changes in the lives of women, defining empowerment as entailing the ability to define the change for themselves, negotiate change,

understand and challenge injustice and inequity, and act towards the achievement of strategic goals that address issues of women's status/position.

Empowerment was seen as a process in which power was challenged, it connoted collective action, the challenging of ideologies and material realities that were pervasive and deeply entrenched, and given the workings of patriarchy, also challenged internalised norms. Empowerment was not merely about individual choices but must address structural factors that perpetuate inequalities, and finally, empowerment could not be fragmented into 'social' empowerment and 'economic' empowerment since the material and non-material lives of women were linked (Sharma et al. 2007: 11-12).

Using these indices of empowerment, the study found that participation in SHGs has improved credit access 
to meet crisis consumption needs, particularly those related to education and health; there is reduced though continued dependence on moneylenders, and group leaders at least have greater opportunities for mobility and a legitimate space in the public realm. However, this did not lead to increased control over resources in the family; only a marginal increase in income at best. In the mean, issues of injustice and violence in the lives of women did not get taken up and on the occasions that they were, it was outside the formal space of the SHG which was dominated by a narrowly defined financial agenda.

The study also found that certain sections of the population such as Dalits, tribals/adivasis and Muslims were excluded from participation in the SHGs, as they were unable to adhere to the need to save regularly, a norm of the SHGs, due to their economically fragile location in the social and material hierarchy. The interest rates are high and kick in immediately and often women have no access to their own credit as there are bureaucratic and banking hurdles.

The Nirantar report is corroborated by a recent study of SHGs in Tamil Nadu by K. Kalpana (Kalpana 2008: 8). She argues that the institutions of the state and the banking system create hurdles in accessing loans and are also discriminatory towards SHGs with primarily Dalit membership. Women are often faced with a 'Hobson's choice' as they are made responsible for the default payments of male members of the household; if they are unable to make their male kin pay off loans they are expelled from membership of the SHG. The prevalence of such bank-induced dropouts from the SHGs means that the access to credit is not based on women's needs but contingent on the credit worthiness of their entire affinal families including fathers- and brothers-in-law (Kalpana 2008: 14-18). Thus, the banks manipulate the SHGs and other community level social networks to decide who can and who cannot be a member of an SHG. Kalpana also shows that corruption and political compulsions of the state affect access to the loans and contribute to conflict which damages group solidarity within the SHG. Dalit women are more disadvantaged as pressure from the banks is translated within the SHG into pressure on them from other members. Vulnerable women faced by unexpected medical expenses or other emergencies leading to difficulties of repayment are harassed and fined for delayed payments (Kalpana 2008: 20).
Significantly, the Nirantar study argues that the SHG discourses are creating new norms for the 'good woman' in a neoliberal framework: one who saves and repays regularly, puts pressure on other group members to do so similarly - indeed this is an important reason for banks preferring to have women's SHGs as clients - and is committed to the welfare of the family. The evidence that men are happy with women's involvement with the SHGs is in keeping with the reality that this engagement in no way challenges unequal power relations within the family. An official of the SHG scheme 'Swashakti', for example, stated that including indicators of the better status of women would distort the whole programme: 'If we start teaching those things then our whole society will collapse and we will have no values and culture left. Whatever we do it should not destroy our family system' (Sharma et al. 2007: 102). Indeed it is 'family values' that make women such desirable people to bank upon: 'women can be located easily ... they cannot run away, leaving their homes; they can be persuaded to repay more easily as they feel shame more quickly and consider non-repayment a matter of family honour', said another official promoting microcredit (Sharma et al. 2007: 95).

This overwhelming focus on the family undermines the idea of a woman as an entity, with rights, interests and needs, which the women's movement has long been struggling for, and therefore counters its ideological premises. The SHGs thus doubly reinforce women's position within the family, making them bear the burden of the debts of family members, and ensuring that family relations remain what they have traditionally been, and therefore do not destabilise the family in any way: both work to the advantage of existing structures of power.

The policymakers of the SHG schemes have confined the notion of empowerment to 'economic' gains, and even within the economics, they have excluded questions of increased entitlements and rights over public resources. There is a narrow and distorted notion of poverty alleviation which most notably places the onus of poverty alleviation on poor women themselves. Reducing the notion of empowerment in this way also meets the objectives of developmental specialists with an instrumental approach to it, such as the Commissioner for Rural Development who stated that women's participation in SHGs 'enables us to achieve the goals of development quickly as messages conveyed through the SHGs are more effective, and 
they learn to value things like child education and family planning' (Sharma et al. 2007: 96).

To sum up, given the narrow thrust of the SHGs, one woman concluded, 'it is a dilemma in my mind how much social action is compatible with micro-finance... we have no time or structure to address social issues'. Instead, SHGs are replicating the asymmetrical power relations in society, and are instrumental in making it possible for private sector global banks to 'leverage the rural economy', as they do not need their own financial infrastructure to enter the economy. This is making possible the entry of international banks like $\mathrm{IClCl}$ and ABN Amro into rural credit markets without too much effort. In addition, block officials try to politically manage the SHGs and circumscribe the capacity of members to directly challenge both state and household patriarchies. There are thus no inherent qualities in SHGs which empower women clients (Kalpana 2008: 34-8).

\section{Conclusion}

If we return to the issues that were raised at the beginning of this article, issues that have been central to the women's movement, it is clear that there is a basic contradiction between the way the women's movement thinks about development (looking at the structures which obstruct women's development and the violence that is part of their everyday lives: poor access to resources and low status within the family, in the community, and in state institutions), and the way the state - whether of its own accord or the behest of wider global forces - perceives development.

Beginning with the sathin programme (which some women's groups supported and collaborated with as it raised critical issues that obstructed the development of women such as violence and denial of access to resources), and continuing through the Total Literacy Campaign (with its potential for collective action and a challenge to both household and state-based patriarchies giving women agency), and finally with the singular focus on SHGs as the key to women's empowerment, the state's systematic subversion of the struggles of the women's movement through its instrumental approach is strikingly evident.

Neoliberal agendas do not require an end to patriarchies, only their management: global and domestic economic forces and their shared ideologies have reduced the idea of women's development/empowerment to a limited financial venture in which the structures of caste, class and patriarchy continue to be reproduced in all essentials. In fact, the hype around microfinance and women's empowerment is providing an entry point for the neoliberal agenda of capturing rural credit markets by riding on the backs of poor disempowered women, all in the name of women's development and women's empowerment. It is time to stop pretending and to return to the central issues of the women's movement: struggling against the violence of patriarchy, its links with caste and class, and the unequal access of women to the power wielded by the state. It is necessary to first deal with the depoliticisation of the people through changes in the vocabulary adopted by policymakers, both at the international and the domestic levels, which have obfuscated the issues feminists have placed before us: the mantra of empowerment will not serve the purpose of a feminist revisioning of the world

\section{Note}

* I have drawn from three sources for the writing of this article: my own participation in an evaluation team on the Women's Development Programme (WDP), Rajasthan, during which I met a number of sathins and other officials of the
WDP and the state bureaucracy, and a paper that I wrote thereafter, 'The Rhetoric and Substance of Empowerment', published in John et al. (2006); and the experiences and published work of Sadhna Saxena and K. Kalpana listed below, and Sharma et al. (2007). 


\section{References}

Chakravarti, Uma (2006) 'The Rhetoric and Substance of Empowerment: Women, Development, and the State', in Mary E. John, Praveen Kumar Jha and Surinder S. Jodhka (eds), Contested Transformations: Changing Economies and Identities in Contemporary India, New Delhi: Tulika Books

John, Mary; Jodhka, S.S. and Jha, Pravin (eds) (2005) Contesting Terrains, New Delhi: Tulika Books

Kalpana, K. (2008) The Vulnerability of 'Self-Help': Women, and Micro-Finance in South India, IDS Working Paper 303, Brighton: IDS
Saxena, S. (2007) 'Education of the Masses in India: A Critical Enquiry', in Krishna Kumar and Joachim Oesterheld (eds), Education and Social Change in South Asia, Delhi: Orient Longman: 408-40

Saxena, S. (2002) 'Nellore Revisited: Locating the Anti-arrack Agitation in its Historical Context', in Aditi Mukherjee and Duggala Vasanta (eds), Practice and Literacy in Research, New Delhi: Sage; 73-89

Sharma, J., Parthasarathy, S.K. and Dwevedi, A. (2007) Examining Empowerment, Poverty Alleviation, Education Within Self Help Groups: A Qualitative Study, Delhi: Nirantar 